\title{
Neuromuscular performance of Bandal Chagui: Comparison of subelite and elite taekwondo athletes
}

\author{
Pedro Vieira Sarmet Moreira ${ }^{\mathrm{a}, \mathrm{b}, *}$, Márcio Fagundes Goethel ${ }^{\mathrm{a}}$, Mauro Gonçalves ${ }^{\mathrm{a}}$ \\ a Laboratory of Biomechanics, State University of São Paulo (UNESP), Rio Claro, SP, Brazil \\ ${ }^{\mathrm{b}}$ Department of Physical Education, Fluminense Federal Institute of Education Science and Technology (IFF), Macaé, RJ, Brazil
}

\section{A R T I C L E I N F O}

\section{Article history:}

Received 24 September 2015

Received in revised form 27 May 2016

Accepted 1 June 2016

\section{Keywords:}

Martial arts

Kinematic

Ground reaction force

Cocontraction

Roundhouse kick

Velocity

\begin{abstract}
A B S T R A C T
With the aim of comparing kinematic and neuromuscular parameters of Bandal Chagui kicks between 7 elite and 7 subelite taekwondo athletes, nine Bandal Chaguis were performed at maximal effort in a selective reaction time design, simulating the frequency of kicks observed in taekwondo competitions. Linear and angular leg velocities were recorded through 3D motion capture system. Ground reaction forces (GRF) were evaluated by a force platform, and surface electromyographic (sEMG) signals were evaluated in the vastus lateralis, biceps femoris, rectus femoris, tensor fasciae lata, adductor magnus, gluteus maximus, gluteus medius, and gastrocnemius lateralis muscles of the kicking leg. SEMG data were processed to obtain the cocontraction indices (CI) of antagonist vs. overall (agonist and antagonist) muscle activity. $\mathrm{CI}$ was measured for the hip and knee, in flexion and extension, and for hip abduction. Premotor, reaction (kinetic and kinematic), and kicking times were evaluated. Timing parameters, except kinetic reaction time, were faster in elite athletes. Furthermore, $\mathrm{CI}$ and angular velocity during knee extension, foot and knee linear velocity, and horizontal GRF were significantly higher in elite than in subelite athletes. In conclusion, selected biomechanical parameters of Bandal Chagui appear to be useful in controlling the training status of the kick and in orienting the training goal of black belt competitors.
\end{abstract}

(c) 2016 Elsevier Ltd. All rights reserved.

\section{Introduction}

In taekwondo, $>90 \%$ of the points in competition are scored by kicks (Kazemi et al., 2010). The most commonly used in competition is the roundhouse kick directed to the thorax (Bandal Chagui), which results in the majority of points (Estevan and Falco, 2013). To be successful, taekwondo competitors need to kick fast (Moreira et al., 2014; Falco et al., 2009; Jakubiak and Saunders, 2008). Additionally, to generate enough kinetic impact energy to score points on electronic protectors, a high linear velocity of leg segments is required (Ramazanoglu, 2013; Tasika, 2013; Estevan and Falco, 2013). The linear velocity of leg segments is in turn a direct result of muscular moment and the interaction of the angular momentum of leg joints (Quinzi et al., 2014; Kim et al., 2010; Sørensen et al., 1996).

In kicks, the angular momentum of the leg segment and joints are determined by the angular velocities of these segments (Quinzi et al., 2014, 2015; Sørensen et al., 1996). Furthermore, the interaction of agonist and antagonist muscle recruitment is

\footnotetext{
* Corresponding author at: Street: Dois de Dezembro, $\mathrm{n}^{\circ}$ 35, Ap.: 1002, Rio de Janeiro, RJ 22220-040, Brazil.

E-mail address: sarmet_treinamento@hotmail.com (P.V.S. Moreira).
}

an important determinant of the angular velocity (Sørensen et al., 1996; Sbriccoli et al., 2010). This interaction is traditionally visualized through the cocontraction index (Quinzi et al., 2013, 2015). A greater cocontraction implies a higher antagonist muscle opposition to the intended movement. This strategy also has beneficial roles in joint stabilization during impact (Thibordee and Prasartwuth, 2014), and in the fine control of movement accuracy (Osu et al., 2002; Sbriccoli et al., 2010). The cocontraction strategy can be influenced by a number of factors, i.e., the expertise level, martial modality and the used joint (Sbriccoli et al., 2010; Quinzi et al., 2013; Thibordee and Prasartwuth, 2014). To date, the information gathered in studies investigating other martial arts, other expertise levels or on different joints cannot be successfully applied to taekwondo.

Additionally, some temporal and kinetic parameters have been identified as being important to the performance in taekwondo because, to be fast, a kick needs to be performed with a low total response time (Estevan et al., 2012), which is composed of the reaction time (Moreira et al., 2014; Chung and Ng, 2012; Estevan et al., 2013; Falco et al., 2012), the preparation phase time (Moreira et al., 2015; Pozo et al., 2011), and the kicking phase time (Moreira et al., 2015; Falco et al., 2012, 2009). Moreover, because 
the peak of the ground reaction force (GRF) is inversely correlated with execution time and directly correlated with the velocity of the thigh, shank and foot (Moreira et al., 2015; Estevan et al., 2013), to reach a high level of GRF, it is important to perform an efficient kick.

The aforementioned data lead us to believe that comparing the neuromuscular performance of different level athletes in carrying out relevant techniques for their fights might provide an initial but important understanding of the biomechanical mechanisms by which higher competitive-level athletes are more efficient in applying these techniques. To date, some researchers have already compared the performances of martial athletes of different competitive levels, based on their general physical and physiological profile (Bridge et al., 2014), but only a few of them have studied the effect of performance in specific movements of combat, such as roundhouse kicks, on athletes' expertise level (Estevan and Falco, 2013; Quinzi et al., 2013). Quinzi et al. (2013) compared athletes of karate, while Estevan and Falco (2013) focused only on the impact effect and temporal aspects of kicks on athlete expertise level. Therefore, the goal of this study was to compare execution time, linear and angular velocity, ground reaction force, and electromyographic parameters between taekwondo athletes of two different standards in a selective reaction time design. We hypothesized that elite level athletes would be able to show better Bandal Chagui performance than subelite athletes as a result of specific neuromuscular adaptations through the interaction of more efficient training and individual genetics. Consequently, it is to be expected that elite athletes have superior velocity and ground reaction force, while simultaneously, they present faster premotor time, reaction time, kick time, total time and different antagonistagonist interactions than subelite athletes.

\section{Methods}

\subsection{Participants}

Fourteen black belt competitors were divided into two groups, as follows: 7 elite athletes (five male and two female finalists or semifinalists in national competitions, including four national champion and three champions of various international competitions; $23.6 \pm 2.1$ years; $69 \pm 9.5 \mathrm{~kg} ; 168 \pm 5 \mathrm{~cm}$ with leg length of: $832 \pm 20 \mathrm{~mm} ; 1.3 \pm 0.8$ Dan; $12.2 \pm 8.5$ years of training; $15.7 \pm 4.7 \mathrm{~h}$ per week of training) and 7 subelite athletes (five male and two female finalists or semifinalists in state competitions without qualify for or achieve good classification in national competitions; $22.4 \pm 1.3$ years; $66.8 \pm 14.2 \mathrm{~kg} ; 174 \pm 11 \mathrm{~cm}$; with leg length of: $861 \pm 52 \mathrm{~mm} ; 1.0 \pm 0.0 \mathrm{Dan} ; 10.4 \pm 6.1$ years of training; $11.4 \pm 5.1 \mathrm{~h}$ per week of training), without significant differences between the groups in any anthropometric characteristics, age, graduation (Dan), frequency or time of training.

\subsection{Experimental design}

This study was designed to evaluate the biomechanical parameters of 9 executions of Bandal Chagui intercalated with 9 Dollyo Chagui (roundhouse kick to the head), with a randomized order and timing between visual stimuli, simulating the average number of high intensity activities (18) and the timing between stimuli $(7 \pm 2 \mathrm{~s})$ reported in taekwondo matches (Campos et al., 2012). Both the average time between stimuli and the standard deviation were constructed through a MATLAB routine to generate the closest possible time to that cited by Campos et al. (2012). As a result, the vector of time between stimuli resulted in the exact mean of $7.0354 \mathrm{~s}$ with a standard deviation of $2.0756 \mathrm{~s}$.
In combat, the actions of opponents are unpredictable, and there are many types of techniques used to score (Tornello et al., 2014); here, the reaction time demand for which the athletes are subject is the selective type. Therefore, for the reaction time to be reasonable, it is necessary to have more than one option of response (Borysiuk and Waskiewicz, 2008). For this reason, it was required of the athletes to execute the kick at two different heights depending on the stimulus location, which in this case was visually indicated and generated by the lighting of LEDs located near two possible targets of impact (head and thorax).

When considering the possibility that, when martial athletes perform a relatively high number of kicks, there is some kind of fatigue manifestation (e.g. reduction of Biceps Femoris median frequency and activation magnitude: see Quinzi et al., 2015, 2016), our group previously held a study (not yet published) of the effect of simulating a "Round" on the fatigue of the present volunteer athletes. The results of this preliminary study demonstrated, through the analysis of variance for repeated measures, that in these athletes, there was no reduction in performance $(p>0.05)$ of any variables when measured by means of linear velocity peaks (speed foot, ankle, knee and pelvis), by temporal parameters (reaction time, preparation time, kicking time and the total time of kick performance), or by the average values of agonistic and antagonistic muscle activation. However, it is important to consider that it is possible that the athletes obtain the same performance measures (linear velocity peaks, temporal parameters) with a different technique. Additionally, the comparison of our previous results with the fatigue manifestation demonstrated by Quinzi et al. $(2015,2016)$ needs to be interpreted considering that the differences in Biceps Femoris activation can be motivated by differences in the braking role of this muscle across the two disciplines, taekwondo in the present study and karate in the study of Quinzi et al. (2015, 2016).

\subsection{Data collection}

Before starting the biomechanical data collection, each athlete completed a questionnaire and reported the frequency of training as an average of hours/week and the level of experience by writing the date (year and month) that they started practicing taekwondo. Then, $\mathrm{Ag} / \mathrm{AgCl}$ bipolar electrodes (Miotec ${ }^{\circledR}$ Double, 20-mm interelectrode distance) were placed in 8 muscles (Gastrocnemius Lateralis: GL, Vastus Lateralis: VL, Rectus Femoris: RF, Biceps Femoris: BF, Adductor Magnum: AM, Tensor Fasciae Lata: TFL, Gluteus Maximus: GM and Gluteus Medium: Gmed), individually positioned according to the European Recommendations for Surface Electromyography (Hermens et al., 1999). Each electrode was connected by a wireless transmitter Telemyo DTS (Noraxon ${ }^{\circledR}$ ) at $3000 \mathrm{~Hz}$, with an analog band pass filter operating between 20 and $500 \mathrm{~Hz}$.

For kinematic capture, 39 markers were placed on the athletes' bodies according to the Plug-in Gait marker set. After 15 min of warm up ( $5 \mathrm{~min}$ of running at $8 \mathrm{~km} / \mathrm{h}$ plus 2 min of specific free taekwondo displacement, which is specific footwork for taekwondo combat: step forward, backward, change of direction, etc., and 12 vertical jumps, followed by 10 kicks, with the last 2 at maximal intensity to familiarize with the main evaluation), there was a 5 min rest, and subsequently the principal evaluation, which consisted of 18 roundhouse kicks (9 Bandal Chagui and 9 Dollyo Chagui) with the foot of the dominant leg starting above a force platform OR-6 (AMTI $\left.{ }^{\circledR}\right)$ and spaced a horizontal distance from the dummy (BoomBoxe ${ }^{\circledR}$ ) equivalent to the lower limb length. One LED was placed in the dummy's thorax and another in the dummy's contralateral eye from the impact side, and they were microcontrolled by a MATLAB (MathWorks ${ }^{\circledR}$ 2012, Inc.) routine and randomized in a Gaussian mode, with a mean of $7 \pm 2 \mathrm{~s}$ between 
each one over the course of 2 min (Campos et al., 2012). Athletes were instructed to kick as strong and fast as possible each time the LEDs turned on. The 39 kinematic markers were recorded during the kicks through 7 cameras MX13 $\left(\operatorname{Vicon}^{\circledR}\right)$ at 250 frame/s. Impact power was recorded by the official score system body protector (TK-Strike 4.2, Daedo ${ }^{\circledR}$ ) of national and international events. Then, to mark the exact impact timing and to synchronize electromyography (EMG) with kinetic and kinematic data, one flexible contact platform was developed and placed between the body protector and the dummy. When compressed, this platform simultaneously emitted electric tension $(0-2.5 \mathrm{~V})$ to the EMG receptor (Telemyo DTS Receiver, Noraxon ${ }^{\circledR}$ ) and kinetic synchronization system (Gyganet, Vicon ${ }^{\circledR}$ ) through NOR-BNC cables.

\subsection{Analytical methods}

Data of frequency and experience of training were transferred to an Excel (Microsoft Office ${ }^{\circledR}$ ) datasheet, and the time experience from each athlete was then calculated by subtracting the date of data collection by the date that they started practicing taekwondo. Raw kinetic (ground reaction force - GRF) and kinematic (linear and angular) data were automatically generated by the "Process Dynamic Plug-in Gait Model" operation from the Nexus 2.0 $\left(\right.$ Vicon $\left.^{\circledR}\right)$ software. Kinetic and kinematic data (Figs. 1 and 2) were smoothed through a Butterworth zero-lag Low-Pass filter with the cutoff at $85 \mathrm{~Hz}$ and $10 \mathrm{~Hz}$ (cutoff frequencies determined through residual analysis; Winter, 1990), respectively. Both the offset of kinetic reaction time and onset of the preparation phase of kick were considered to be the time when the resultant ground reaction force systematically (during at least 350 samples) started to increase above the baseline (average value of the next 200 samples from the LED onset) of $2.5 \%$ (this was the threshold where there was the minimal difference between the onset automatically detected and the visual onset) of the difference between the peak GRF and the baseline value. The Offset of the kinematic reaction was considered to be when the pelvis started to move at least $1 \mathrm{~cm}$ from the initial position. Both the offset of the preparation phase and the onset of the kicking phase were when the resultant GRF turned to zero. The end of the kicking phase was when the foot touched the target, i.e., when the contact sensor of the dummy started to increase voltage above $1 \mathrm{~V}$. These events were automatically identified through a MATLAB ${ }^{\circledR}$ routine. Then, the duration of the kinetic reaction time (offset of kinetic reaction time - LED onset), kinematic reaction time (offset of kinematic reaction time - LED onset), preparation phase (offset of preparation phase - onset of preparation phase), kicking phase (onset of target contact - onset of kicking phase) and total kick time (onset of kicking phase - LED onset) were determined (Fig. 2). Rate of force development (RFD) and the peak of the antero-posterior, medio-lateral, vertical and resultant forces were determined during the preparation phase. RFD was calculated as follows:

$\mathrm{RFD}=\Delta$ Force $/ \Delta$ time

with $\Delta$ time being the time between the moment when the force turned to $20 \%$ of the difference from the baseline to the peak force until the moment when the force turned to $80 \%$ of this difference. Below $20 \%$ or above $80 \%$ of this difference, the force signal was not produced in an explosive way, i.e., with low curve inclination. The peak of the angular velocity (from hip joint: frontal, transverse and sagittal plane; knee and ankle joints: sagittal plane) and the linear velocity of the pelvis (anterior superior iliac spine), knee (lateral condyle of femur), ankle (lateral malleolus) and CG foot (Center of Gravity of foot, automatically determined by the NEXUS 2.0 software) during the kicking phase were recorded for comparisons (Figs. 1 and 2). Estevan et al. (2013) showed that the reliability of kinetic and kinematic parameters of the Bandal Chagui in taekwondo athletes can be considered good to excellent (ICC $=0.73-0.97)$.

The impact measurement of each kick was obtained by the True Score System $\left(\right.$ Daedo $^{\circledR}$ ) software, and it was subsequently exported to an excel datasheet. For the kick success rate (\% Points) analyses, the percentage of kicks with impact magnitude equal to or higher than the individual threshold was calculated for each athlete in relation to the total number of carried out kicks. The individual threshold used as a reference to consider a kick valid was defined according to the World Taekwondo Federation (WTF) rules for Olympic categories (WTF, 2015).

Data from the EMG were rectified, smoothed through a Butterworth zero-lag Low-Pass filter at $10 \mathrm{~Hz}$, and normalized through the peak dynamic method (Ball and Scurr, 2013), resulting in an intelligible smoothed signal (Linear Envelop - LE). An example of a LE for each muscle is demonstrated in Fig. 1. In this case, the LE for each muscle shows that the EMG lines are plotted in the same sense as the angular position lines for the muscle agonist function. For example, in Fig. 1, the LE of GL is negative because its muscle function is plantar flexion combining with the negative sense of the kinematical graph representation of ankle movement. To calculate the cocontraction index $(\mathrm{CI})$, the time of the kicking phase was automatically segmented through a MATLAB routine according to its respective kinesiologic action: (a) Hip flexion phase - the time between the onset of the kicking phase and the peak of the hip flexion angular position; (b) Hip abduction phase - the time between the onset of the kicking phase and the peak of hip abduction; (c) knee flexion phase - the time between the onset of the kicking phase and the peak of knee flexion; (d) knee extension phase - the time between the peak of knee flexion and the time of impact with the target. Then, the Cl's between the hip extensor (GM) and flexor (TFL or TFL + RF) during hip flexion, between the knee flexor (BF) and extensor (VL or VL + RF) during knee flexion and extension, and between hip adductor (AM) and abductor (Gmed) during hip abduction were calculated as follows:

$\mathrm{CI}=$ Antagonist $_{\mathrm{LE}} /\left(\right.$ Agonist $_{\mathrm{LE}}+$ Antagonist $\left._{\mathrm{LE}}\right)$,

where "Antagonist $\mathrm{LE}_{\mathrm{LE}}$ and "Agonist $\mathrm{LE}_{\mathrm{LE}}$ are the average values of agonist and antagonist muscle activation, measured through LE processing, respectively. Finally, to calculate the premotor time (PMT), the time between the visual stimulus and onset of LE were determined. The onset of the EMG signal was obtained through two consecutive steps: (1) The determination of the "onset 1" as the first instantaneous sample for which the amplitude of the LE averaged over the subsequent $50 \mathrm{~ms}$ was higher than $10 \%$ of the difference between baseline and the peak value of the LE; (2) Starting from the onset 1, the "final onset" was considered to be the first sample where the value of LE was higher than $1 \%$ of the difference between baseline and the peak value of LE. The percentage threshold values and the time window used to determine the EMG onset were the combination where the automatic onset was closest to the visual onset. For this purpose, during various pilot tests, several combinations of time windows ( $10 \mathrm{~ms}, 25 \mathrm{~ms}, 50 \mathrm{~ms}$ and $100 \mathrm{~ms})$ and thresholds ( $1 \%, 2.5 \%, 5 \%, 7.5 \%$ and $10 \%)$ were tested. Qualitatively through graphics of the mean and average of various repetitions, Quinzi et al. (2013) demonstrated that the EMG activation patterns during the Round House Kick showed high reproducibility in martial athletes.

\subsection{Statistical analysis}

Statistical analysis was carried out using SPSS 18.0 (SPSS Inc., Chicago, IL). The Shapiro Wilk test was used to analyse the data's normality, and the independent student t-test was used to compare biomechanical parameters between groups of athletes. When there was no data normality, the Mann Whitney test was used to com- 

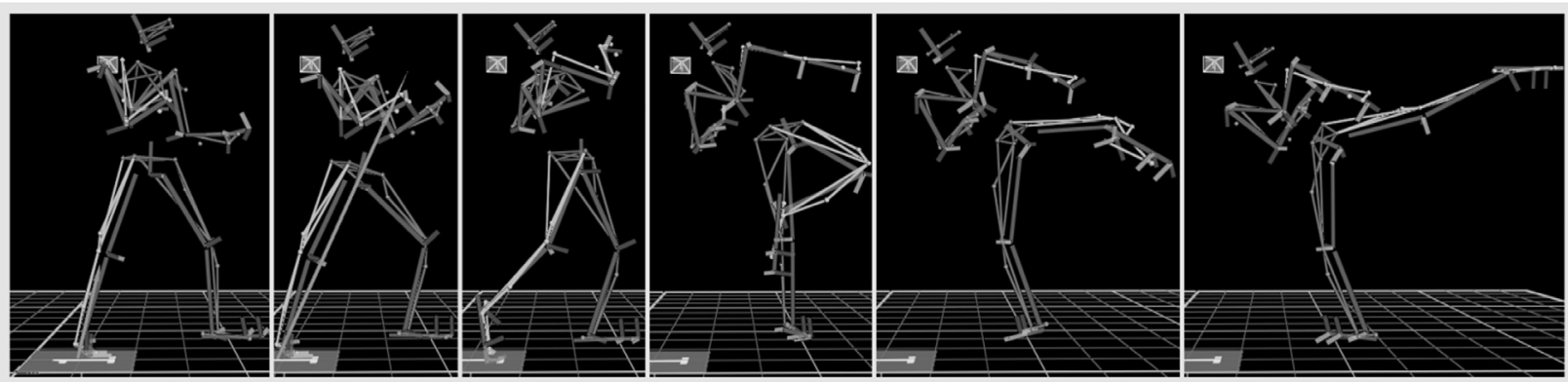

Hip Extension (-) Flexion (+)

Hip Adduction (-) Abduction (+)

Ankle PltFlx (-) DrsFlx (+)
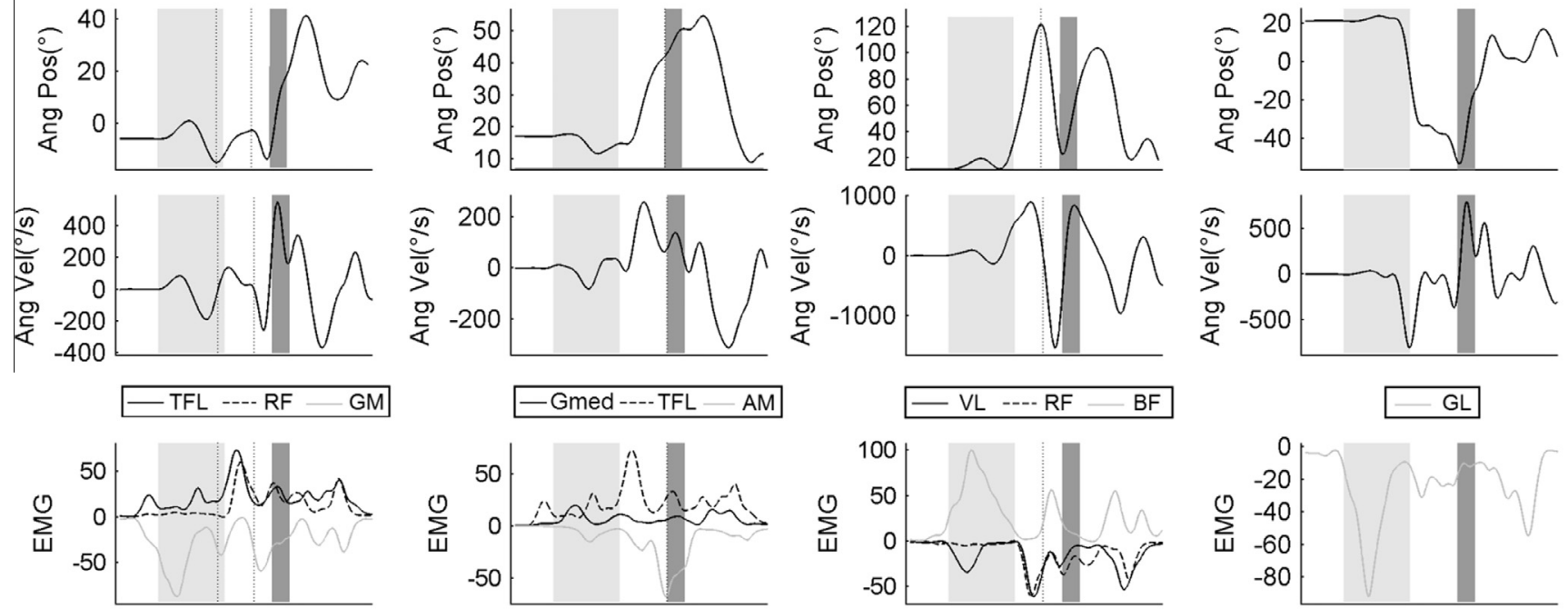

Hip Rot Int (-) Rot Ext (+)

Pelvis AP: CCW (-) CW (+)

Pelvis ML: CW (-) CCW (+)

Pelvis Long: CW (-) CCW (+)
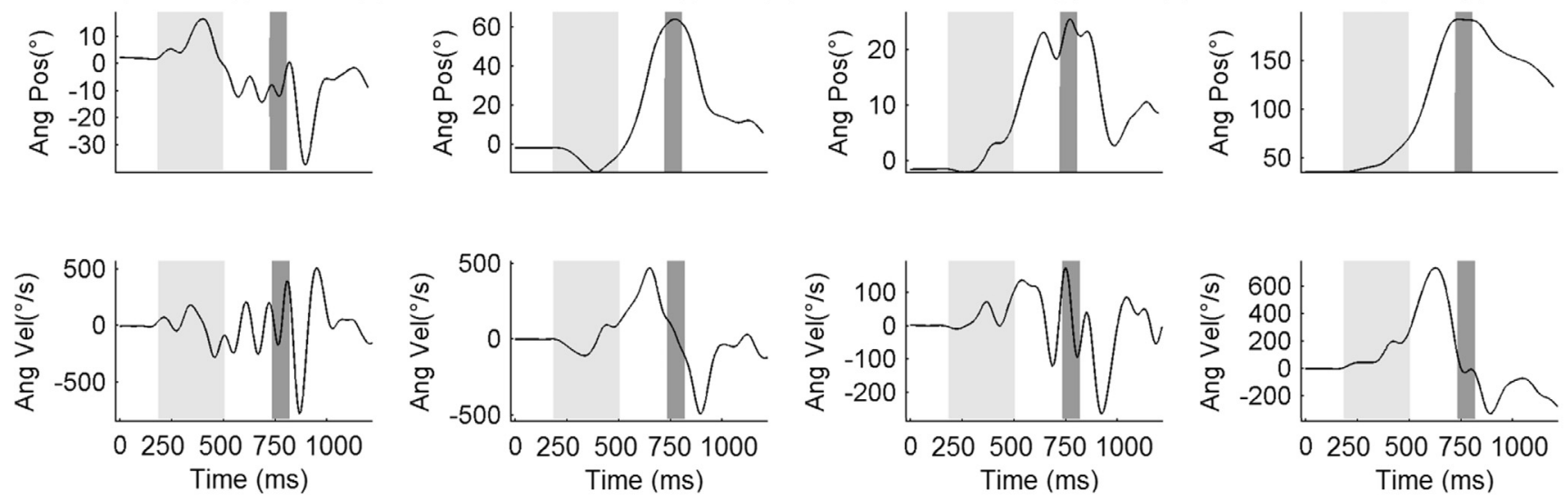

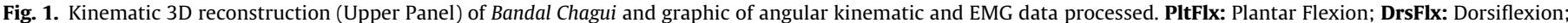

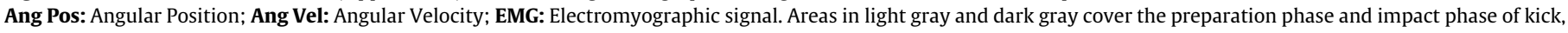

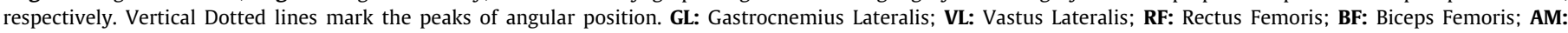

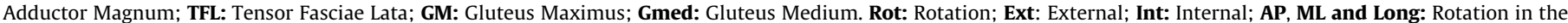
antero-posterior, medio-lateral and longitudinal axis, respectively; CW: Clock wise sense; CCW: Counter clock wise sense.

pare groups. The level of statistical significance was set at $\mathrm{P}<0.05$. Differences obtained from the student $t$-tests and the Mann Whitney tests were quantified through Cohen's $d$ score to analyse the effect size of comparisons (Mullieneaux et al., 2001). A $d$ value $\geqslant 0.8$ indicated a large effect, 0.79-0.5 a moderate effect, 0.49-0.2 a small effect, and $<0.2$ a trivial effect (Cohen, 1988). The sample calculation, previously based on 10 volunteers ( 5 elite athletes and 5 subelite athletes), which demonstrated an average difference between athlete groups of $106 \mathrm{~ms}$ in the total kick time and $1.8 \mathrm{~m} / \mathrm{s}$ in the foot velocity, showed that it was necessary in the unpaired student $t$-test to, respectively, have 7 and 5 volunteers in each group, to have an $80 \%$ chance of detecting a difference of $106 \mathrm{~ms}$ in the total kick time and $1.8 \mathrm{~m} / \mathrm{s}$ in the linear velocity of the foot.

\section{Results}

\subsection{Frequency of training and experience}

The elite athletes have $12.2 \pm 8.5$ years of training experience, while the subelite athletes have $10.4 \pm 6.1$ years of training, without a significant difference $(\mathrm{p}>0.05)$. Additionally, the frequency 

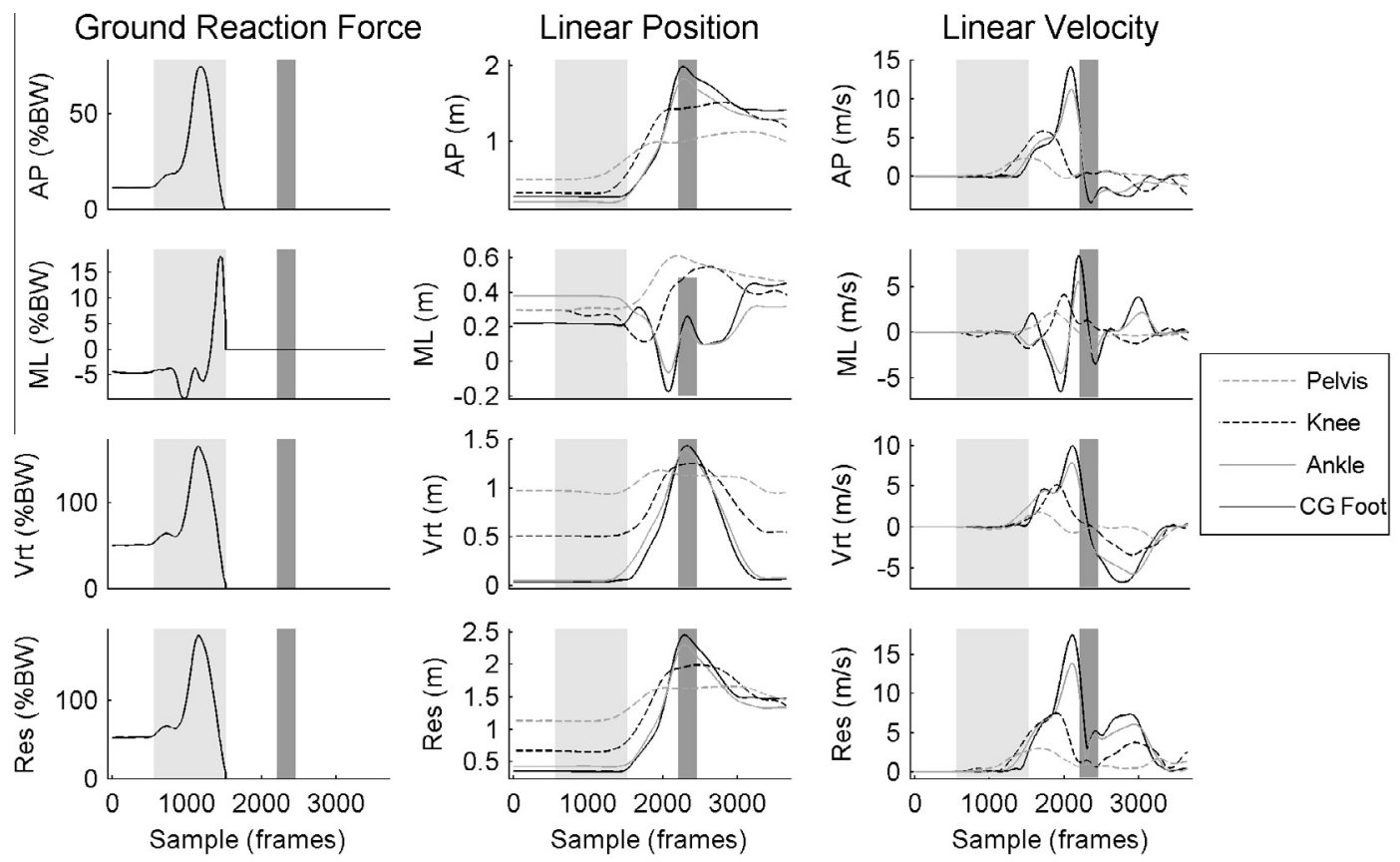

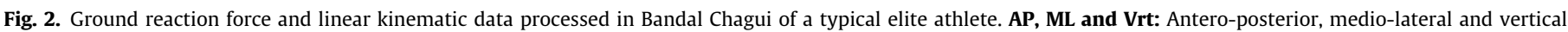

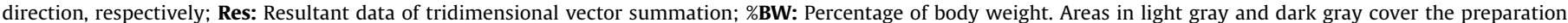
phase and impact phase of kick, respectively.

of training in the elite athletes was $15.7 \pm 4.7 \mathrm{~h}$ per week, while in the subelite athletes, it was $11.4 \pm 5.1 \mathrm{~h}$ per week of training, without a significant difference $(\mathrm{p}>0.05)$.

\subsection{Execution and premotor time of the kick}

Descriptive data and comparative analysis between groups in timing and premotor time of kicks are shown in Fig. 3. It was observed that elite athletes had faster kinematic reaction time $(\mathrm{p}<0.01)$ to start to move the pelvis after the visual stimulus. Also, they need less time in the preparation phase $(p<0.01)$, kicking phase $(\mathrm{p}<0.05)$ and total kicking time $(\mathrm{p}<0.01)$. Furthermore, it was observed that only the premotor times of the gastrocnemius lateralis and gluteus maximus were faster $(p<0.05)$ in the elite athletes compared to subelite athletes.

\subsection{Kinematics of the kick}

Descriptive graphics and comparative analysis of the linear velocity of the leg segments in kicks between groups are shown in Fig. 3. Results show that the elite athletes performed kicks with a higher velocity of the knee ( $p<0.01)$ and foot segment $(p<0.05)$. Graphics of descriptive statistics and comparative analysis between athlete groups for the pelvis segment, hip and knee joint peak angular velocities are shown in Fig. 4. Elite athletes demonstrated greater angular velocity of hip external $(p<0.05)$ and internal rotation $(p<0.05)$, and also for knee flexion $(p<0.05)$ and extension $(\mathrm{p}<0.01)$.

\subsection{Cocontraction index}

Fig. 4 shows indices of cocontraction obtained for the biceps femoris and quadriceps muscles (rectus femoris and vastus lateralis) during both knee flexion and knee extension phases, for the gluteus maximus and hip flexor muscles (rectus femoris and tensor fasciae lata) during the hip flexion phase, and for the adductor magnus and hip abductor muscles (gluteus medius and tensor of fascia lata) during the hip abduction phase. The elite group demonstrated superior cocontraction indices compared to the subelite competitors only in muscles that control the knee extension $(\mathrm{p}<0.05)$.

\subsection{Kinetics of the kick}

Results of the rate of force development against the ground and the peak of ground reaction forces of both athlete groups are depicted in Fig. 5. Elite competitors presented higher peak ground reaction forces in medio-lateral $(p<0.01)$, antero-posterior $(\mathrm{p}<0.05)$ and resultant $(\mathrm{p}<0.05)$ directions than subelite athletes. Athletes with better competitive results also presented superior performances in the resultant rate of force development $(p<0.05)$ compared to athletes of an inferior level. Vertical ground reaction force was borderline $(p=0.052)$ significantly higher in elite than subelite athletes.

The magnitude of impact (Fig. 5) and the percentage of kicks (Elite: $\mathrm{Mdn}=100 \%$ success score rate, $\mathrm{IQR}=22.2 \%$; Subelite: $\mathrm{Mdn}=77.8 \%$ success score rate, $\mathrm{IQR}=22.2 \%$ ) with potential for score points (i.e.: kicks with equal or higher measured impact than the minimal threshold defined for each weight category) were similar between groups of athletes (Impact Magnitude: $p=0.147 ; \%$ Points: $\mathrm{p}=0.454$ ).

Values of effect sizes (Cohen's $d$ ) from all statistical comparisons realized between elite versus subelite athletes are presented in Table 1. All significant parameters in the statistical comparisons between athlete groups had large effect sizes $(d=0.87-1.44)$.

\section{Discussion}

With the aim to compare the neuromuscular performance of the Bandal Chagui kick between subelite and elite standard taekwondo athletes, kinetic, kinematic and electromyographic parameters were evaluated. Results demonstrated that elite athletes have a faster premotor reaction time of selected muscles, resulting in a higher level of horizontal ground reaction forces; conse- 

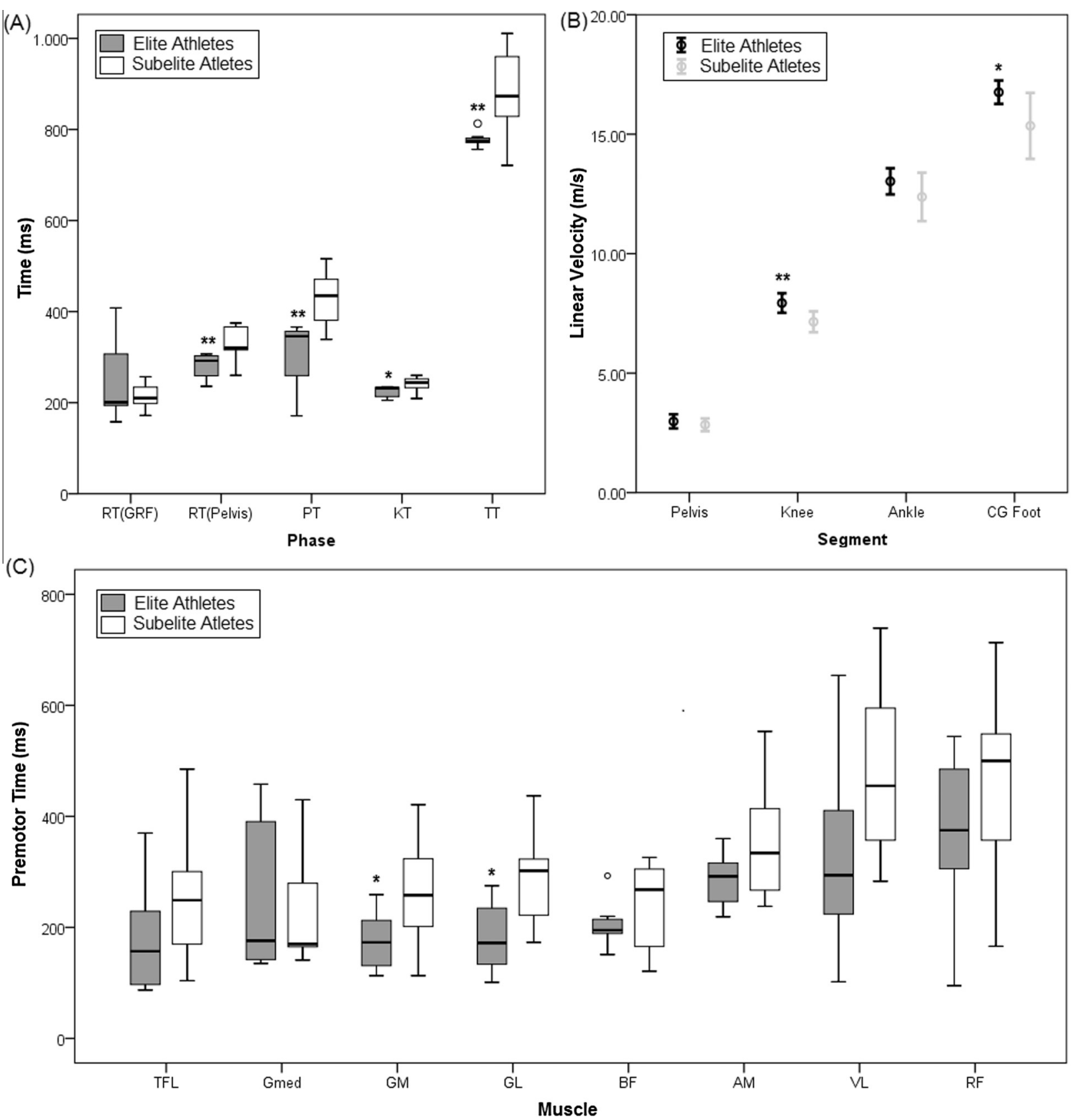

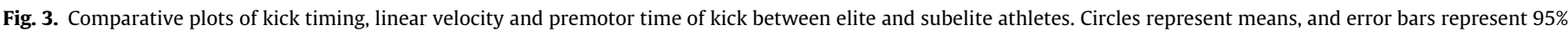

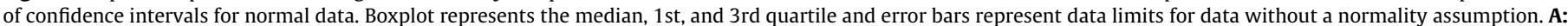

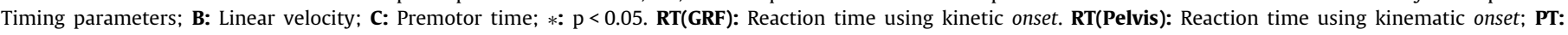

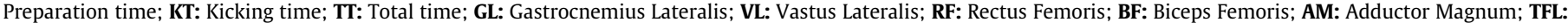
Tensor Fasciae Lata; GM: Gluteus Maximus; Gmed: Gluteus Medium.

quently, the moment was anticipated when the elite athletes started to move their pelvis and shortened the preparation time compared to subelite athletes. Elite athletes also presented faster kicking times; consequently, they presented faster total performance times than subelite athletes. In addition, elite athletes presented a higher cocontraction index of the muscles controlling knee extension and a higher angular velocity of hip rotations, knee flexion and knee extension. Additionally, elite athletes presented a higher peak linear velocity of the knee and foot; however, these achievements were not enough to result in a significantly higher kick impact.

Although the timing parameters and the velocity are the main determinant biomechanical parameters of performance in taek- wondo athletes (Estevan et al., 2013; Falco et al., 2012, 2009; O'Sullivan et al., 2009), the impact magnitude needs to be high enough to reach thresholds specific for each athlete's weight category (Ramazanoglu, 2013). In this study, the average impact of each athlete was higher than the minimal threshold of impact necessary to score points in his or her respective weight division according to World Taekwondo Federation (2015) rules. Once athletes have the capacity to reach high enough kick impact magnitudes to gain points in competition, they can concentrate on obtaining high velocity, faster reaction times and kick executions. This strategy can be justified considering that kick velocity and kick timing are central biomechanical parameters for taekwondo performance because to score points, athletes need to be faster 

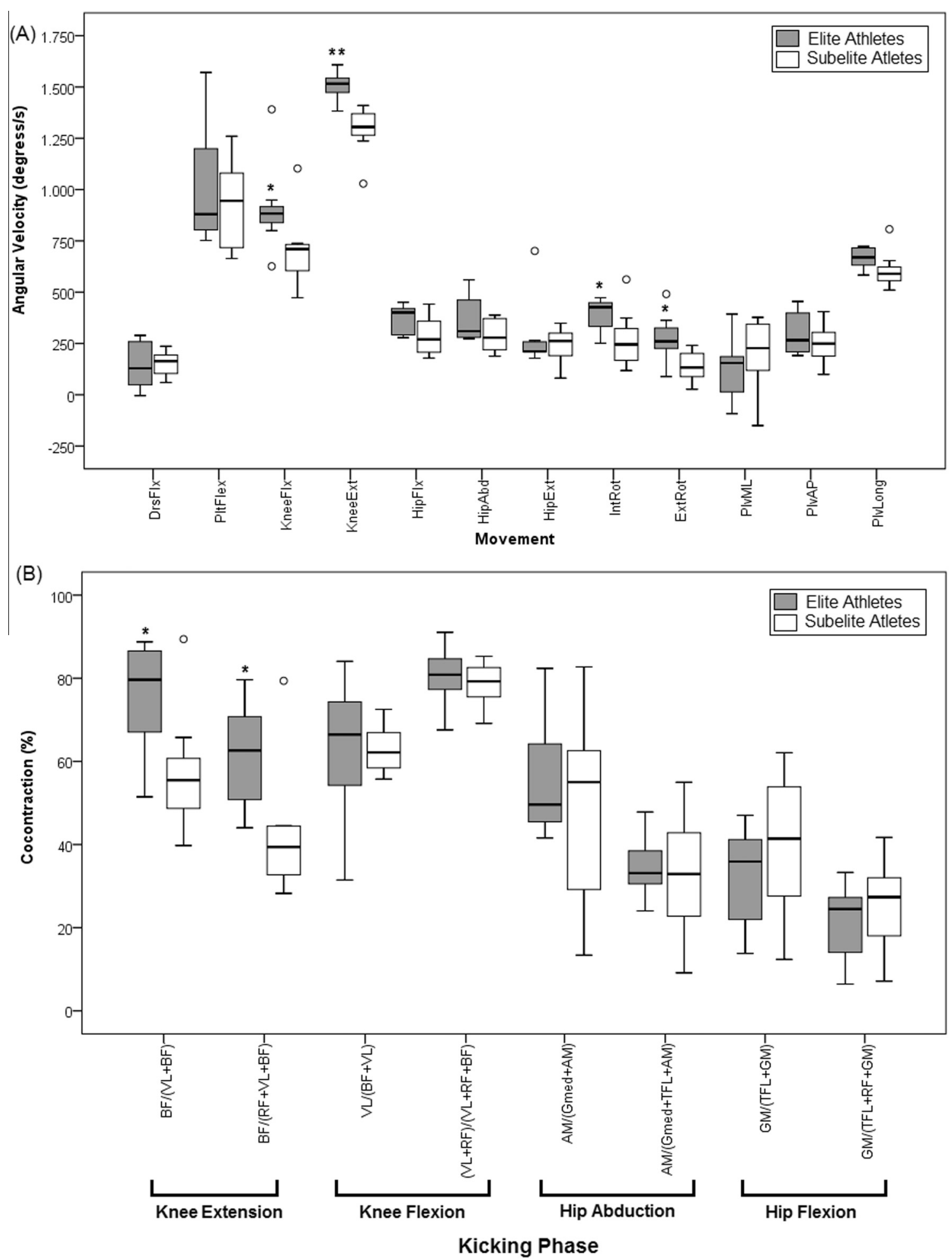

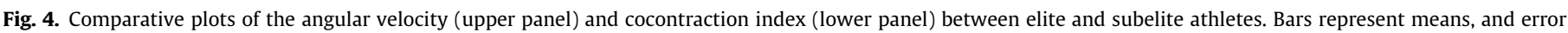

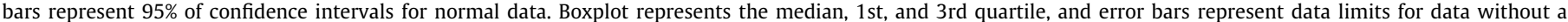

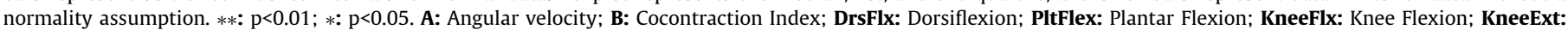

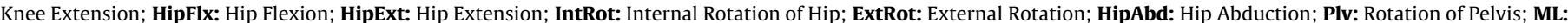

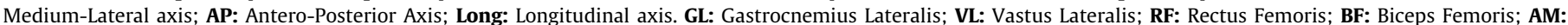
Adductor Magnum; TFL: Tensor Fasciae Lata; GM: Gluteus Maximus; Gmed: Gluteus Medium.

than their opponents (Kim et al., 2010; Jakubiak and Saunders, 2008; Kazemi et al., 2010; Falco et al., 2012). In this study, the elite athletes presented superior knee and foot linear velocity compared to subelite athletes, who showed a foot linear velocity similar to what was found by Estevan et al. (2013), who found it to be $14.42 \pm 2.69 \mathrm{~m} / \mathrm{s}$. However, our elite athletes presented a foot linear velocity slightly lower than that found by O'Sullivan et al. (2009), who found it to be $17.66 \pm 1.67 \mathrm{~m} / \mathrm{s}$. 

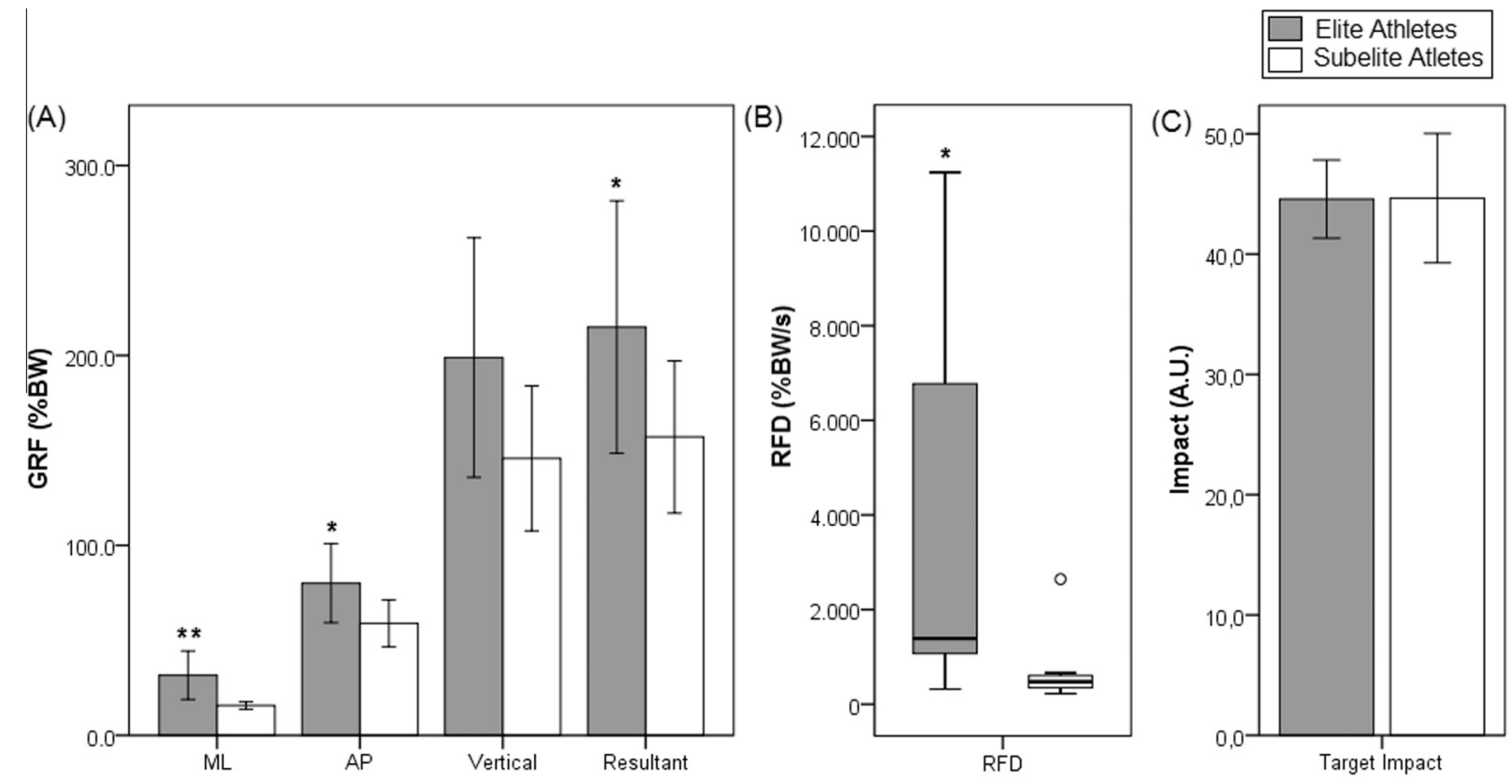

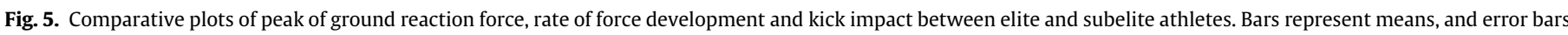

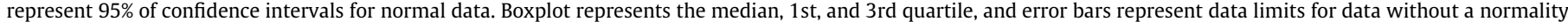

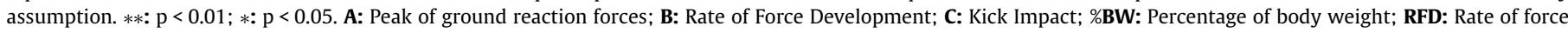

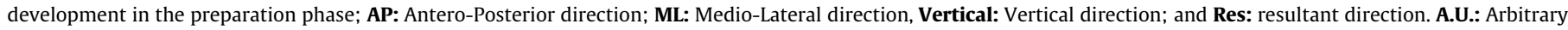
Unity of impact patented by Daedo ${ }^{\circledR}$.

Table 1

Effect sizes (Cohen's $d$ ) from statistical comparisons between elite versus subelite athletes.

\begin{tabular}{|c|c|c|c|}
\hline Parameter & $d$ & Parameter & $d$ \\
\hline \multirow[t]{2}{*}{ Kick time } & & Premotor time & \\
\hline & & GL & $1.11^{*}$ \\
\hline $\mathrm{RT}(\mathrm{GRF})$ & 0.49 & $\mathrm{VL}$ & 0.78 \\
\hline RT(Pelvis) & $1.18^{* *}$ & $\mathrm{RF}$ & 0.51 \\
\hline PT & $1.27^{*}$ & $\mathrm{BF}$ & 0.44 \\
\hline KT & $0.98^{*}$ & TFL & 0.59 \\
\hline $\mathrm{TT}$ & $1.18^{* *}$ & GM & $0.95^{*}$ \\
\hline Ground reaction forces & & Gmed & 0.24 \\
\hline Peak force AP & $1.01^{*}$ & AM & 0.75 \\
\hline Peak force ML & $1.27^{* *}$ & Cocontraction & \\
\hline Peak force Vrt & 0.87 & $\mathrm{BF} /(\mathrm{VL}+\mathrm{BF})$ & $1.02^{*}$ \\
\hline Peak force Res & $0.90^{*}$ & $\mathrm{BF} /(\mathrm{RF}+\mathrm{VL}+\mathrm{BF})$ & $1.04^{*}$ \\
\hline RFD & $0.98^{*}$ & $\mathrm{VL} /(\mathrm{BF}+\mathrm{VL})$ & 0.02 \\
\hline Angular velocity & & $(\mathrm{VL}+\mathrm{RF}) /(\mathrm{BF}+\mathrm{VL}+\mathrm{RF})$ & 0.30 \\
\hline Dorsiflexion & 0.04 & $\mathrm{AM} /(\mathrm{Gmed}+\mathrm{AM})$ & 0.42 \\
\hline Plantar flexion & 0.40 & $\mathrm{AM} /(\mathrm{Gmed}+\mathrm{TFL}+\mathrm{AM})$ & 0.18 \\
\hline Knee flexion & $0.88^{*}$ & $\mathrm{GM} /(\mathrm{GM}+\mathrm{TFL})$ & 0.50 \\
\hline Knee extension & $1.44^{* *}$ & $\mathrm{GM} /(\mathrm{GM}+\mathrm{TFL}+\mathrm{RF})$ & 0.51 \\
\hline Hip flexion & 0.82 & Linear velocity & \\
\hline Hip extension & 0.35 & Pelvis & 0.47 \\
\hline Hip internal rotation & $0.87^{*}$ & Knee & $1.31^{* *}$ \\
\hline Hip external rotation & $1.11^{*}$ & Ankle & 0.71 \\
\hline Hip abduction & 0.77 & Foot & $1.08^{*}$ \\
\hline Pelvis ML & 0.43 & Kick impact & \\
\hline Pelvis AP & 0.51 & $\%$ Points & 0.20 \\
\hline Pelvis Lgt & 0.70 & Magnitude & 0.02 \\
\hline
\end{tabular}

d: Effect Size; RT(GRF): Reaction time using kinetic onset. RT(Pelvis): Reaction time using kinematic onset; PT: Preparation time; KT: Kicking time; TT: Total time; GL: Gastrocnemius Lateralis; VL: Vastus Lateralis; RF: Rectus Femoris; BF: Biceps Femoris; AM: Adductor Magnum; TFL: Tensor Fasciae Lata; GM: Gluteus Maximus; Gmed: Gluteus Medium; RFD: Rate of force development in the preparation phase; AP: Antero-Posterior; ML: Medio-Lateral, Vrt: Vertical, Res: resultant, Lgt: Longitudinal axis.

${ }_{* *}^{*} \mathrm{p}<0.05$.
According to the actual results, there was no difference in the kinetic reaction time "RT(GRF)", but subelite athletes produced forces against the ground in a more explosive way and with a higher magnitude. If the present data of GRF are transformed to Newton's unity, we can compare them with Estevan et al. (2013), who found a peak of antero-posterior, medial-lateral, vertical and resultant GRF varying from $349 \mathrm{~N}$ to $375 \mathrm{~N}, 73 \mathrm{~N}$ to $123 \mathrm{~N}, 707 \mathrm{~N}$ to $758 \mathrm{~N}$, and $789 \mathrm{~N}$ to $844 \mathrm{~N}$, respectively. Consequently, obtained performances by our elite athletes in GRF (Antero-Posterior: $542 \pm 162 \mathrm{~N}$; Medio-Lateral: $211 \pm 86 \mathrm{~N}$; Vertical: $1334 \pm 446 \mathrm{~N}$ ) were superior to those reported by Estevan et al. (2013). However, the present values of GRF were similar to that obtained by high level athletes (Moreira et al., 2015), who achieved $645 \pm 162 \mathrm{~N}$, $285 \pm 283 \mathrm{~N}$ and $1200 \pm 227 \mathrm{~N}$ for Antero-Posterior, Medio-Lateral and Vertical peaks of GRF, respectively. Additionally, the subelite group in this study had similar performances in GRF (AnteroPosterior: $396 \pm 159 \mathrm{~N}$; Medio-Lateral: $104 \pm 33 \mathrm{~N}$; Vertical: $991 \pm 490 \mathrm{~N}$ ) to those reported by these authors. The inferior magnitude of horizontal forces and the rate of force production against the ground obtained by our subelite athletes can explain why subelite athletes started to move the pelvis later than elite athletes, and why the preparation phase was slower in subelite athletes, characterizing a less efficient impulse. The findings of Estevan et al. (2013), which showed positive correlations $(r>0.72)$ between the horizontal GRF and linear peak velocities of the thigh, can also explain why elite athletes presented superior thigh linear velocity.

An important component of the reaction time is the premotor time (Chung and $\mathrm{Ng}$, 2012). This parameter is a neural component of the reaction time, as it denotes the speed of neural transmission and information processing (Chung and Ng, 2012). In the elite athletes of the present study, the gastrocnemius lateralis (GL) and gluteus maximus (GM) muscles presented a faster premotor time when compared to subelite athletes. The contraction of the GM and GL contributes to generating the forward displacement of the pelvis because the GL is a plantar flexor muscle, while the 
GM is a hip extensor muscle. Once elite athletes have activated these muscles earlier than subelite athletes, GRF production by these muscles can be anticipated, so that the peak horizontal force can benefit from it. Thus, these faster premotor reaction times contributed to elite athletes generating higher horizontal ground reaction force peaks, resulting in a faster preparation phase. This is in accordance with McLean et al. (2010), who demonstrated that during a specific choice reaction task (leg landing), GL and biceps femoris pre-motor times were associated with the peak knee abduction moment. Chung and $\mathrm{Ng}$ (2012) demonstrated that professional taekwondo athletes had faster premotor times than amateurs or non-athletes for sport specific stimuli (i.e.: a photograph of a TKD athlete performing a side kick attack motion), but this had not occurred for simple visual (a green circle on a gray background of the computer monitor) and auditory (single beep sound) stimuli. The opposite happened for non-specific stimuli, i.e., the professional group responded slower than the non-professional. This indicates the ability of professional athletes to focus on relevant (specific) stimuli from the combat scene, decreasing sensibility to irrelevant stimuli. In the present study, the stimuli were visual (two LEDs), but the data collection scenario was prepared to reproduce the competitive environment because the simulated opponent (a training dummy) had physical similarities to the appearance of a real human opponent. Additionally, by using the international (WTF, 2015) official trunk and head protector, the stimuli and the target were placed in relevant dummy body segments (thorax and head) to score points in the WTF (WTF, 2015) rules of a combat, in a selective reaction time design. Furthermore, the kind of analyzed reaction movement (Bandal Chagui Kick) was a specific movement to the taekwondo modality.

One of the most important indices of performance is the total response time (TT) because it includes the reaction time, preparation time and kicking time, in a unique parameter, determining the capacity of a kick response to result in a scored point. However, investigating only this parameter does not allow us to find the sources of possible differences. In this study, there was a difference between groups in TT; furthermore, the total response time averages reported by Estevan and Falco (2013) in expert competitors $(773 \mathrm{~ms})$ and novices $(838 \mathrm{~ms})$ were similar to those obtained in the present study by the elite and subelite athletes, respectively. It has been previously demonstrated by Falco et al. (2009) that the kicking phase time (KT) was able to be used to discriminate the expertise level of competitors. The data of the present study allow the same conclusion. Significant differences in KT were found between groups. Furthermore, in this study, the subelite athletes had similar KT than the competitors $(239 \pm 25 \mathrm{~ms})$ reported by Falco et al. (2009), and they obtained faster KT than the noncompetitor athletes $(279 \pm 46 \mathrm{~ms})$ reported by this same author during the kicks at a medium distance. Additionally, the elite athletes of the present study demonstrated a higher performance than both competitors and non-competitors reported by Falco et al. (2009) and the Korean athletes (330 $\pm 30 \mathrm{~ms}$; O'Sullivan et al., 2009).

The angular kinematic is the key point to understand how the linear movement of segments was processed by the athletes (Kim et al., 2010; Sørensen et al., 1996). A previous study with karate has already compared joint angular roundhouse kick velocity between athlete groups with different competitive rankings, and it found that karate elite athletes demonstrated a higher knee and hip peak angular velocity compared to amateurs (Quinzi et al., 2013). Similarly, in the present study, higher angular flexion and extension speed was found in the elite athletes compared to the subelite group. However, in the hip joint, only the rotations (internal and external) were different between groups, with the superior performance in the elite group. The peak angular velocity obtained in this study presented slightly lower peak angular velocity for the knee (flexion $=916 \pm 234 \mathrm{deg} / \mathrm{s}$ in elite and $709 \pm 203 \mathrm{deg} / \mathrm{s}$ in subelite group; extension $=1506 \pm 72 \mathrm{deg} / \mathrm{s}$ in elite and $1288 \pm 129 \mathrm{deg} / \mathrm{s}$ in subelite group) and hip extension $(\mathrm{Mdn}=273, \mathrm{IQR}=55 \mathrm{deg} / \mathrm{s}$ in elite and $\mathrm{Mdn}=262, \mathrm{IQR}=173 \mathrm{deg} /$ $\mathrm{s}$ in subelite group) compared to those reported by Quinzi et al. (2013) (Knee Flexion $=1333 \pm 165$ in elite and $812 \pm 125 \mathrm{deg} / \mathrm{s}$ in subelite athletes; Knee Extension $=1734 \pm 108$ in elite and $1315 \pm 117 \mathrm{deg} / \mathrm{s}$ in subelite athletes; Hip Extension $=608 \pm 62$ in elite and $426 \pm 107 \mathrm{deg} / \mathrm{s}$ in subelite athletes) and O'Sullivan et al. (2009) (Knee Extension $=1586 \pm 181 \mathrm{deg} / \mathrm{s}$ and Hip Extension $=693 \pm 115$ in Korean university athletes). Possible explanations for these differences could be the different filtering technique in data processing or the differences in the volunteers' sport level between the studies. The present study adopted a stricter low pass filtering (cutoff: $10 \mathrm{~Hz}$ ) compared to the studies of O'Sullivan et al. (2009) and Quinzi et al. (2013), which used a cutoff frequency of $15 \mathrm{~Hz}$ and $20 \mathrm{~Hz}$, respectively, to smooth the data. In the actual study, the time of the kicking phase (KT) of both athlete groups was faster than that reported by O'Sullivan et al. (2009) and Quinzi et al. (2013). This comparison indicates the first alternative, i.e., the influence of filtering technique in the reported results.

To test if the filtering technique influenced the differences of angular velocities between studies, we decided to process the kinematic data of our elite athletes with a less conservative low pass filtering (cutoff: $20 \mathrm{~Hz}$ ). Consequently, it was found similar velocities of knee flexion $(1060 \pm 410 \mathrm{deg} / \mathrm{s})$ than that reported by Quinzi et al. (2013) and similar or higher velocity of knee extension $(1856 \pm 150 \mathrm{deg} / \mathrm{s})$ than the achieved by the athletes from the study of Quinzi et al. (2013) and O'Sullivan et al. (2009). However, even with the least conservative filtering, the athletes of the present study had lower velocities of hip extension $(405 \pm 255 \mathrm{deg} / \mathrm{s})$ than those found by the aforementioned authors. To interpret this result, it is important to consider the differences between karate and taekwondo concerning the techniques and the neuromuscular adaptation of the biceps femoris. In Karate, the athletes cannot kick with full contact (Quinzi et al., 2013, 2015, 2016); therefore, acquiring a superior velocity of hip extension as a consequence of the deceleration of the hip flexion movement should be an adaptive solution to avoid a strong impact. The high velocity of knee extension (Quinzi et al., 2013) should be a result of the motion dependent moment caused by the hip flexion deceleration (Sørensen et al., 1996). This is not a problem for karate athletes because they are trained to suddenly contract the biceps femoris as a strategy to avoid strong impact (Quinzi et al., 2013; Sbriccoli et al., 2010).

The cocontraction index is another important parameter because it is associated with the performance level of martial kicks (Quinzi et al., 2013; Thibordee and Prasartwuth, 2014), differentiating between fast elite and slow subelite athletes (Quinzi et al., 2013) or between athletes that perform high impact or low impact Bandal Chagui (Thibordee and Prasartwuth, 2014). The present study only found differences between groups in the cocontraction of muscles that control the knee extension. Elite athletes presented a superior cocontraction index than subelite athletes. In a similar technique (Mawashi Geri), karatecas obtained the opposite of the current results, i.e., the elite athletes presented an inferior cocontraction index compared to subelite athletes in the same muscles (Quinzi et al., 2013). On the other hand, when the cocontraction of the biceps femoris and rectus femoris was measured in the Bandal Chagui of taekwondo, athletes with superior performance presented a higher coactivation magnitude of the biceps femoris during the impact, which was credited to joint stabilization (Thibordee and Prasartwuth, 2014). Higher values of cocontraction during knee extension in elite athletes, credited to knee joint stabilization obtained in the present study, are attributed to the fact that the impact target (center of dummy) of Bandal Chagui was 
heavy, and also to the higher peak of the angular velocity in knee extension presented by elite athletes compared with subelites. Combined, these factors may imply large knee joint moments (Quinzi et al., 2014, 2015, 2016). In fact, the lower limbs, particularly the knee joint, are the body locations with the greatest incidences of injuries in taekwondo (Pieter, 2005). Furthermore, the main activity performed during these occurrences was just the roundhouse kick (Pieter, 2005). In this technique, the bigger coactivation index of the biceps femoris is a protection factor for the knee joint because the cocontraction of this muscle was correlated with the peak of the leg angular momentum during the kick (Quinzi et al., 2015). According to Quinzi et al. (2015), given the very brief duration of the roundhouse kick, there is a feedforward mechanism modulating antagonist activation, partly based on the stress imposed on the knee joint. This mechanism potentially involves skill-dependent remodeling of the peripheral and central nervous system (Quinzi et al., 2015).

The findings provided in this study should be considered in the framework of the following limitations. First of all, given the small sample size, some non-significant results may be related to a lack of statistical power. Then, the negative findings should be interpreted with caution. However, the small sample size was compensated by the selective sample composition, mainly for the elite group. On the other hand, the fact that the sample size obtained was not higher than the number stated by the sample calculation, associated with the fact that all significant results in statistical comparisons had high effect sizes, provided us a protective factor against type I errors, which could be associated with the large number of parameters analyzed. Secondly, the kick impact unity was not according to the international physical system (SI). Nevertheless, it was in an arbitrary unity of impact measure, created and patented by the industry of impact sensors to be used as a reference by the World Taekwondo Federation (2015) in official competitions. It becomes difficult to infer with precision the mechanical factors that generate the measured impact by these systems. On the other hand, the same impact measurement system (Daedo ${ }^{\circledR}$ body protector) that is utilized by athletes during official competitions by the World Taekwondo Federation was used in this study. Therefore, in this case, the goal of simulating the mechanical component of the competitive environment during the data collection was reached.

\section{Conclusion}

In conclusion, elite athletes presented a higher performance than subelite athletes in a large number of parameters for an efficient Bandal Chagui, such as the premotor reaction time of selected muscles (GL and GM), the kinematic reaction time of pelvis movement, the preparation, kicking and total time, linear speed of leg segments, ground reaction forces and the peak of the angular speed during hip rotation and knee flexion-extension. As the higher knee angular speed obtained in elite athletes was accompanied by a superior cocontraction index of muscles that control this movement (hamstrings and quadriceps), we attributed this muscular phenomenon to joint stabilization. It resulted in similar kick impacts between both groups of athletes, although the impact magnitudes were enough to score points in each analyzed athlete, independent of the competitive level. This way, the presented parameters that differed between athlete groups could be useful for coaches to design specific training methods to improve the kick performance of athletes. For example, (a) athletes can be instructed to try to contract the GM and GL quickly during reaction time training; (b) coaches could use scientific information available in sport literature to design training that aims to make the preparation time faster but improves the strength and rate of force produc- tion through dynamic/similar activities, having done the necessary adaptations to adjust the training for the specificity of the movement, such as kicking against a resistive band, and performing plyometric training combined with kicks; (c) speed training that aims to increase the linear speed of the knee and foot or exercises to speed up knee flexion/extension and hip rotation movements seem to be a good strategy to apply and study for their practical results; and (d) when an athlete becomes capable of developing a fast and strong kick impact, if the goal is to increase the safety of movements in order to prevent injuries in the knee joint or in hamstring muscles, subelite athletes may be asked to contract these muscles with greater intensity during the knee extension phase of Bandal Chagui. Additionally, the specific neuromuscular and technical differences between groups found in this study also indicate that when evaluated in a well-equipped center of high performance, these parameters could be useful for monitoring the specific training status of high-level taekwondo athletes. This research used expensive equipment, but for practical purposes, important parts of the variables that differentiated the standard level of athletes can be assessed by relatively cheap and accessible devices at high performance centers, such as the electro-goniometers for angular velocities and the combination of LEDs and contact platforms for the temporal parameters of the kicks.

\section{Acknowledgement}

This work was supported by the Fundação de Amparo à Pesquisa do Estado de São Paulo (FAPESP) under grant [\#2012/19093-6].

\section{References}

Ball, N., Scurr, J., 2013. Electromyography normalization methods for high-velocity muscle actions: review and recommendations. J. Appl. Biomech. 29 (5), 600608.

Borysiuk, Z., Waskiewicz, Z., 2008. Information processes, stimulation and perceptual training in fencing. J. Hum. Kinet. 19, 63-82.

Bridge, C.A., Santos, J.F.S., Chaabène, H., Pieter, W., Franchini, E., 2014. Physical and physiological profiles of taekwondo athletes. Sports Med. 44 (3), 713-733.

Campos, F.A.D., Bertuzzi, R., Dourado, A.C., Santos, V.G.F., Franchini, E., 2012. Energy demands in taekwondo athletes during combat simulation. Eur. J. Appl. Physiol. 112 (4), 1221-1228.

Chung, P., Ng, G., 2012. Taekwondo training improves the neuromotor excitability and reaction of large and small muscles. Phys. Ther. Sport 13, 163-169.

Cohen, A., 1988. Statistical Power Analysis for the Behavioral Sciences, second ed. Lawrence Erlbaum Associates, Mahwah, NJ.

Estevan, I., Falco, C., 2013. Mechanical analysis of the roundhouse kick according to height and distance in taekwondo. Biol. Sports 30 (4), 275-279.

Estevan, I., Falco, C., Alvarez, O., Molina-García, J., 2012. Effect of olympic weight category on performance in the roundhouse kick to the head in Taekwondo. J. Hum. Kinet. 31, 37-43.

Estevan, I., Jandacka, D., Falco, C., 2013. Effect of stance position on kick performance in Taekwondo. J. Sports Sci. 31 (16), 1815-1822.

Falco, C., Alvarez, O., Castillo, I., Estevan, I., Martos, J., Mugarra, F., Iradi, A., 2009. Influence of the distance in a roundhouse kick's execution time and impact force in Taekwondo. J. Biomech. 42, 242-248.

Falco, C., Molina-García, J., Alvarez, O., Estevan, I., 2012. Effects of target distance on select biomechanical parameters in taekwondo roundhouse kick. Sports Biomech. 12 (4), 381-388.

Hermens, H., Freriks, B., Merletti, R., Hagg, G., Stegeman, D., Blok, J., Rau, G., Disselhorst-Klug, C., 1999. European recommendations for surface electromyography. RRD, Netherlands 8 (2), 13-54.

Jakubiak, N., Saunders, D.H., 2008. The feasibility and efficacy of elastic resistance training for improving the velocity of the Olympic Taekwondo Turning Kick. J. Strength Cond. Res. 22, 1194-1197.

Kazemi, M., Perri, G., Soave, D., 2010. A profile of 2008 Olympic Taekwondo competitors. J. Can. Chiropr. Assoc. 54 (4), 243-249.

Kim, J.W., Kwon, M.S., Yenuga, S.S., Kwon, Y.H., 2010. The effects of target distance on pivot hip, trunk, pelvis, and kicking leg kinematics in Taekwondo roundhouse kicks. Sports Biomech. 9, 98-114.

McLean, S.G., Borotikar, B., Lucey, S.M., 2010. Lower limb muscle pre-motor time measures during a choice reaction task associate with knee abduction loads during dynamic single leg landings. Clin. Biomech. 25 (6), 563-569.

Moreira, P.V.S., Crozara, L.F., Goethel, M.F., Paula, L.V., Vieira, F., 2014. Talent detection in taekwondo: which factors are associated with the longitudinal competitive success? Arch. Budo 10, 295-306. 
Moreira, P.V.S., Paula, L.V., Veloso, A.P., 2015. Segmental kick velocity is correlated with kick specific and nonspecific strength performance in a proximodistal sequence. Arch. Budo 11, 271-276.

Mullieneaux, D.R., Bartlett, R.M., Bennett, S., 2001. Research design and statistics in biomechanics and motor control. J. Sports Sci. 19, 739-760.

Osu, R., Franklin, D.W., Kato, H., Gomi, H., Domen, K., Yoshioka, T., Kawato, M., 2002. Short-and long-term changes in joint co-contraction associated with motor learning as revealed from surface EMG. J. Neurophysiol. 88, 991-1004.

O'Sullivan, D., Chung, C., Lee, K., Kim, E., Kang, S., Kim, T., Shin, L., 2009 Measurement and comparison of taekwondo and yongmudo turning kick impact force for two target heights. J. Sports Sci. Med. 8, 13-16.

Pieter, W., 2005. Martial arts injuries. Med. Sport Sci. 48, 59-73.

Pozo, J., Guillaume, B., Dierick, F., 2011. Execution time, kinetics, and kinematics of the mae-geri kick: comparison of national and international standard karate athletes. J. Sports Sci. 29 (14), 1553-1561.

Quinzi, F., Camomilla, V., Felici, F., Di Mario, A., Sbriccoli, P., 2013. Differences in neuromuscular control between impact and no impact roundhouse kick in athletes of different skill levels. J. Electromyogr. Kinesiol. 23 (1), 140-150.

Quinzi, F., Sbriccoli, P., Alderson, J., Di Mario, A., Camomilla, V., 2014. Intra-limb coordination in karate kicking: effect of impacting or not impacting a target. Hum. Mov. Sci. 33, 108-119.

Quinzi, F., Camomilla, V., Felici, F., Di Mario, A., Sbriccoli, P., 2015. Agonist and antagonist muscle activation in elite athletes: influence of age. Eur. J. Appl. Physiol. 115 (1), 47-56.

Quinzi, F., Camomilla, V., Di Mario, A., Felici, F., Sbriccoli, P., 2016. Repeated kicking actions alter technical execution in elite karate practitioners. Int. J. Sports Physiol. Perform. 11 (3), 363-369.

Ramazanoglu, N., 2013. Transmission of impact through the electronic body protector in taekwondo. Int. J. Appl. Sci. Technol. 3 (2), 1-7.

Sbriccoli, P., Camomilla, V., Di Mario, A., Quinzi, F., Figura, F., Felici, F., 2010. Neuromuscular control adaptations in elite athletes: the case of top level karateka. Eur. J. Appl. Physiol. 108, 1269-1280.

Sørensen, H., Morten, Z., Simonsen, E.B., Dyhre-Poulsen, P., Klausen, K., 1996. Dynamics of the martial arts high front kick. J. Sports Sci. 14 (6), 483-495.

Tasika, N., 2013. Reliability \& linearity of an electronic body protector employed in taekwondo games: a preliminary study. J. Hum. Sport Exercise 8, 622-632.

Thibordee, S., Prasartwuth, O., 2014. Effectiveness of roundhouse kick in elite Taekwondo athletes. J. Electromyogr. Kinesiol. 24 (3), 353-358.

Tornello, F., Capranica, L., Minganti, C., Chiodo, S., Condello, G., Tessitore, A., 2014 Technical-tactical analysis of youth Olympic Taekwondo combat. J. Strength Cond. Res. 28 (4), 1151-1157.

Winter, D.A., 1990. Biomechanics and Motor Control of Human Mouemerit, second ed. Wiley-Interscience, Toronto, Ontario.

World Taekwondo Federation. Competition Rules. <http://www.wtf.org/wtf_eng/ site/rules/competition.html> (accessed 21 September 2015).

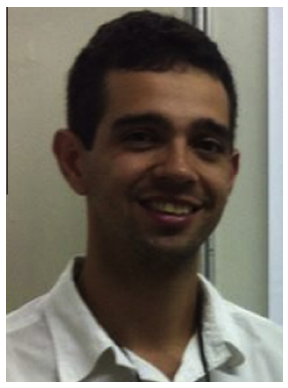

Pedro Vieira Sarmet Moreira PhD in Biomechanics an Master in Training for High Performance. He acts on the following subjects: Biomechanics, Kinesiology, Sports Training, Body Composition, Maturation and Performance, Explosive Strength Training, Power, Coordination and Speed, Bioenergetics, Fatigue, Performance and Martial Arts.

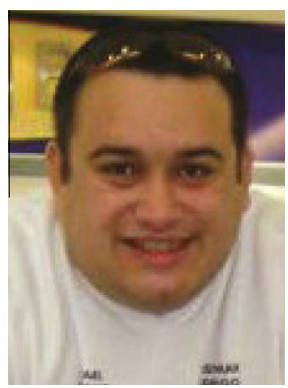

Marcio Fagundes Goethel PhD in Biomechanics. He has experience in Biomechanics, with emphasis on signal processing, spine implant, Karate and Judo.

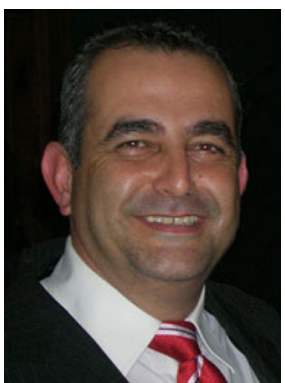

Mauro Gonçalves is coordinator of Laboratory of Biomechanics from UNESP in which he conducts its research on analysis of human movement through kinematics, kinetics and electromyography, with emphasis on muscular action in several sports, on the fatigue process and in fall of elderly people. He is a former President of the Brazilian Society of Biomechanics - SBB and former Chief Editor of the Journal MOTRIZ. He is also member of the Scientific Committee of the SBB. 